\title{
Chapter 9 \\ Simulation as an Approach \\ to Social-Ecological Integration, \\ with an Emphasis on Agent-Based Modeling
}

\author{
Randall B. Boone and Kathleen A. Galvin
}

\subsection{Introduction}

In past decades ecological and social science research took pathways that intersected in meaningful ways only infrequently. In ecology, humans were viewed as causes of change external to the systems of interest, or as sources of variation controlled for in experiments so that human influences could be ignored. In anthropological research, ecological settings have been explored and debated as a means to understand human evolution, societal development and power over resources (e.g., Orlove 1980; Watts 1997; Boyd and Richerson 2005). Concepts were mutually borrowed by each discipline from the other (e.g., evolution, niche theory, commons theory), but active integration was uncommon and sometimes even discouraged. The roles that humans play as components of systems became a focus in the second half of the last century, and queries with humans considered as a component of ecosystems were more common (e.g., Rappaport 1967; Liverman et al. 1998; Little and Leslie 1999) (see Sect. 9.3). However this systems view of humans did not allow for agency or diversity and was highly criticized in the social sciences (e.g., Moran 2008). Today, questions regarding sustainability are so broad in scope and outcomes so important to societies that scientific fields are being invented to address new questions about linkages within systems (see Part I of this volume). An example of institutional

\footnotetext{
R.B. Boone $(\bowtie)$

Natural Resource Ecology Laboratory, Colorado State University,

1499 Campus Delivery, B234 Natural and Environmental Sciences Building,

Fort Collins, CO 80523-1499, USA

K.A. Galvin

Department of Anthropology, Colorado State University,

1787 Campus Delivery, Fort Collins CO 80523-1787, USA
} 
recognition of the importance of understanding these linkages is in the Dynamics of Coupled Natural and Human Systems competition in the US National Science Foundation. Each year millions of dollars are put to increasing our understanding of linkages between humans and the ecosystems they inhabit.

A main tool to understand linkages of societies and their environments is through the use of computer simulation. Simulation is a broad term, describing "... a class of symbolic models, which are representations of particular facets of reality ..." (Galvin et al. 2006). Here we confine our discussion to the kinds of simulation models often used to represent coupled natural and human systems. These are a class of models called discrete-event simulations, where analysis steps are simulated to represent the passage of time, and events are scheduled to occur at particular points in time. Simulations are often processed-based, where processes describing interactions between system elements are described mathematically in computer code, or rule-based, where thresholds and logical bifurcations are described in code and represent decision making or other system attributes. Simulations often include stochastic components. The simulations may be point-based, meaning that they represent a single element of a system such as a plant or a person, and the results from that plant or person are taken to hold for other plants or people in the area considered homogeneous by the model. Alternatively, simulations may be spatially explicit, meaning they represent real-world locations where questions of sustainability are at issue.

Simulation approaches have been used in ecological research for decades (e.g., Huston et al. 1988) and more recently in the social sciences (e.g., Brenner 1999; Kohler and Gumerman 1999). Simulation methods are transforming social sciences by adding experimentation to the toolbox of researchers. Hypotheses that may be impractical to assess in reality because of expense, complexity, or moral constraints may be assessed using computer simulations. In what follows, we describe the utility of simulation in general terms, then specific to integration of social and ecological sciences. A pathway we and others use to discovery called integrated modeling is described. Agent-based modeling (ABM) is defined and its role in scientific integration is described. Examples from our work and from the literature are then given to provide context, and we conclude.

\subsection{Utilities of Simulations}

Constructing computer simulations requires that researchers make the interactions and assumptions that are implicit in mental models explicit (Epstein 2008). Primary processes to be included (e.g., primary production) must be distinguished from processes judged appropriate to ignore (perhaps groundwater contributions to primary production), rules must be defined, and parameter values that help describe how elements interact are identified. In a collaborative effort team members of different disciplines come together to share ideas and data. Each team member uses implicit mental models to understand how the system functions, but many people have never 
made those models explicit. Making processes, rules, and parameters explicit can be an illuminating, rewarding, and challenging exercise. For example, for a group to work well together requires a understanding of required terms and some baseline desire and ability to communicate to scholars in other disciplines. Reaching common understanding on what the most salient components of a system may be and how those will be represented in a simulation promotes team building across disciplines (Axelrod 2006).

We agree with Epstein (2008) that the assumption many make of models is that their goal is to make predictions. Predictions can be made but often the assumptions of such models are so simplifying as to have little purchase in the real world. Myriad interactions and unforeseen changes make detailed predictions about future system states all but impossible in all but trivial circumstances. Prediction is rarely the goal of our work. Instead, we often seek to identify the magnitude and direction of change that may be expected in a system, for example, given the changes a particular policy or land management decision may make on the environment and for human wellbeing. Other work by ourselves and others uses hypothetical landscapes, and tests theory without being encumbered by specific circumstances (Griffin 2006).

More generally, simulation can explain relationships, which is distinct from prediction (Epstein 2008). Alternative core dynamics may be incorporated in simulations, and those dynamics treated as hypotheses to be tested in experiments (Peck 2004; Grimm and Railback 2006). For example, the influence of topography on animal behavior may be quantified by using the observed topography in simulations, then substituting a flat landscape. Simulation can guide data collection, with sensitivity analyses (i.e., varying a parameter across its reasonable range of values and exploring changes in output) identifying new questions and uncertainties and allowing data collection efforts to be prioritized. Gaps in understanding can be suggested if an application that incorporates current theory is unable to generate the expected responses. Complex patterns can be shown to have simple underpinnings (e.g., the classic graphic of the Mandlebrot set used to demonstrate the nature of fractals) and simple patterns may be shown to be produced by relationships more complex than assumed (Epstein 2008). Simulation is helpful where analytical, differential equation-based approaches may become mathematically complex and intractable. Lastly, simulation is helpful when manipulations to real systems would be too costly, disruptive, or unethical (Peck 2004).

\subsection{Integrated Modeling}

Ecologists have developed in-depth knowledge about many elements in systems, although much remains to be learned. Prior to the 1980s, a majority of experiments on species interactions were on plots of $1 \mathrm{~m}^{2}$ or less (Kareiva and Andersen 1988). New pathways of exploration and enabling technologies fostered a new type of ecological research exploring spatial scale and macroecology (Gaston and Blackburn 2000; Schneider 2001). But the pace of integrating and synthesizing 
information has been slow (Carpenter et al. 2009). In the 1960s to 1980s social science borrowed ecological terms and analyses such as energy flow studies, adaptation studies and the ecosystem concept and several important studies emerged (e.g., Vayda and McCay 1975; Thomas 1976). But increasing complexity was brought into these studies of human-environment interactions including landscape history (Crumley 1994), policy and power (e.g., Brosius 1997; Escobar 1998) and cultural meanings (Peet and Watts 1996; Berkes 1999). These were aided by new tools such as geographic information systems (GIS) and participatory mapping. New conceptual models that included micro-cultural processes like perception and macro-societal processes such as globalization at various scales were recognized as important elements of research in human-environment interactions (e.g., Liverman et al. 1998).

Subfields in ecology and social science disciplines are once again rapidly developing in large part due to advances in tools such as remote sensing, GIS and modeling. Other current impetuses are a growing human population, increasing stressors on landscapes from local to global scales, and a demand by the public that science address real-world, practical problems likely to have societal impacts. Sustainability science has emerged to address complex problems at the intersection of ecological and social science, with contributions from engineering, atmospheric, and medical sciences. Sustainability science goes beyond traditional hypothesis testing, and instead addresses real-world problems that "blend[s] theory and analysis with political awareness and policy concerns" (Galvin et al. 2006:159). Transdisciplinary teams of ecologists, anthropologists, and others come together to address questions of resilience, adaptive capacities that includes issues of inequality, class, gender and justice, and the sustainability of social-ecological systems (e.g., Folke et al. 2002; Berkes et al. 2003; Leach et al. 2012).

At the core of sustainability science endeavors to understand coupled systems are often computer models that are linked together in an integrated way. In general, the goal of this integration is to have the services ecosystems provide (MEA 2005) influence the behavior and conditions of people and societies, and in turn, to have human decisions and behaviors influence ecosystem services. Different models simulate different components of a coupled system, and many blueprints are used. For example, a hydrology model may be used to represent river flows, an ecosystem model simulates forest growth and carbon sequestration, and an agent-based model (see Sect. 9.4) may represent timber harvesters (see Sect. 9.5 for examples from our work). Often these are well-established models that have been used in discovery for years. New is the effort to link these models together to create an integrated system that includes both humans and the environment. Team members think deeply about their own fields and the simulation tools that each uses, and consider the points of connection between fields. In the example, primary connections may include the harvest of timber, economic benefits from harvest, and increased water runoff from harvested hillsides. The team identifies secondary and tertiary connections as well, perhaps including temperature changes in streams or changes in microclimates (Beschta et al. 1987), and decides what is to be included in connections between models, and excluded. The models are then linked either loosely or tightly (Galvin et al. 2006), a continuum of connectedness depending on the models being 
used and the questions being asked. Methods used in linking models and other considerations are beyond our scope here [see An and López-Carr (2011) and other entries in that special issue for an introduction]. The goal is to create an integrated set of computer simulation models that support assessment of future conditions under different decision pathways. Generally, even with quite simple constituent models, coupled systems models provide sufficient so-called levers and other controls to address a variety of scenarios.

\subsubsection{Ecological and Social Models}

More than a decade of working with integrating models has given us the impression that ecosystem models are more advanced than social system models for understanding the system, though there have been decades of social research into economic behavior, evolutionary behavior and market behavior (e.g., Cangelosi and Parisi 2001; Camerer et al. 2003). Four reasons for this occur to us, although these reasons are inter-related. First, despite the great distance between ecological theory and physics, ecosystems as subjects of natural science include more components that can be modeled through processes rather than using the rule-based approach most often adopted in societal models. An example we use in teaching comes to mind - image tossing 100 chickens into the air along some compass bearing, and mapping their landing places. If those chickens were dressed and frozen, one could predict their landing places quite accurately. But if those same chickens were alive, prediction would be all but impossible. Instead we must be content with describing a mean landing place and some deviation around that. Adding the freewill of the animal makes all the difference. Nobel laureate Richard Feynman put it more succinctly when he said "Imagine how much harder physics would be if electrons had feelings!" In short, societal models are replete with behaviors influenced by the free will of agents. This leaves models of social dynamics more likely to include a rule-based approach.

Second, ecosystems are more self-similar than human communities. Technically, the spatial autocorrelation in ecosystems is higher than in human neighborhoods. Imagine two forest patches separated by perhaps $10 \mathrm{~km}$. What we know about the first patch is likely to apply, to some large degree, to the second patch. Now image a neighborhood of a few city blocks. What we may know about one family is likely not applicable to a family a few blocks away. Indeed, families living as neighbors may be quite distinct from each other. Our third point is closely related to our second. Ecologists are more comfortable than anthropologists at treating their subjects as similar units. Ecologists consider a herd of animals and emphasize the similarities. Anthropologists consider a group of people and see variability. The variability that is inherent within human populations has implications for power, poverty, inequality, development and ultimately sustainability of the social-ecological system. This is not to say that generalizations are not sought after; they are, but differences have real implications for people and the environment. 
The fourth reason that comes to mind may be an outcome of the reasons already cited. There has been a greater embrace of simulation modeling in ecosystem science than in social sciences, and for a much longer time. By the 1980s, manuscripts were published that summarized the strides made in simulation modeling in ecology (e.g., Huston et al. 1988), whereas international meetings on social simulation only began this century, and the community pursuing social simulation is much smaller.

\subsubsection{Integrated Modeling with Stakeholders}

A utility of simulation we will highlight because of its role in our work is its ability to facilitate incorporating stakeholder and local knowledge into a research and modeling effort. Residents of the systems of interest may be interviewed or join in focal groups or meetings to share information. That information may then be used to parameterize integrated models. A suite of methods are now used that formalize gathering of local knowledge, including participatory role games, participatory geographic information science and participatory simulation. When creating rules that describe decision making by people managing or competing for resources, model builders or facilitators gather stakeholders and have them play games that help inform researchers about the decision making process stakeholders use in an area (e.g., Janssen and Ostrom 2006). For example, participants may be asked to role-play as managers of a local fishery, and the decisions made by participants may be emulated in rules used in simulation. Participatory GIS entails meetings with residents to discuss the spatial location and timing of events, the location of entities, their spatial attributes, decision making in using spatial resources, etc. (e.g., Talen 2000). Landscape representations used in these efforts may be on computer screens, printed paper maps, topographic paper mâché models, or simple sketches in the sand. In participatory modeling (e.g., Becu et al. 2008), stakeholders are involved directly in developing computer simulations, either in the model used in discovery or in some simplified version. This work can be challenging, ensuring that concepts such as simulation and scenario analyses are conveyed to participants well, but can be effective. Reid et al. (2009) emphasizes that work intended to involve, educate, and empower local people should encourage frequent sharing of information.

An undervalued use of the products from integrated assessments that we have seen is that they can provide a common starting point in discussions. Meetings between stakeholders can be more focused by demonstrating simulation results. Results from "what if" questions they had proposed are presented and discussed. Participants then have a common starting point, or even a common antagonist, from which to build discussions. Models sometimes influence decision making - often not to the degree that modelers would prefer - but at least relationships that may be forgotten about or ignored in causal considerations are included in discussions that have as their starting point results from comprehensive computer simulations. 


\subsection{Agent-Based Modeling}

Agent-based modeling is distinct from statistical analysis and interpretation of data, equation-based analytical approaches to discovery, and numerical modeling of system dynamics. In analytical approaches, formulas are used that represent changes in system states. An example is Mathusian population change through time: $\mathrm{P}_{t}=\mathrm{P}_{0} \mathrm{e}^{\mathrm{rt}}$, where $\mathrm{P}_{0}$ is an initial population size, $r$ is a growth rate, $t$ is time, and $P_{t}$ is the population at that time (see Turchin 2001 for a more complete treatment). An evident feature of such an approach is that the entity being modeled is the entire population. The same is true for numerical modeling of systems (e.g., Stella is a popular example of software used in such work; IEEE systems, Lebanon, New Hampshire, US), although they adopt a simulation approach. Populations known as stocks are modified at rates set by model designers, and during simulations portions of populations flow into other stocks. Analytical approaches take a top-down approach to discovery, with the structure of the population represented by hypotheses the analyst has incorporated into equations (Grimm 1999).

Agent-based modeling uses a bottom-up approach to discovery (Grimm 1999) that recognizes that individuals are the basic units of decision making, and determine (at least in part) population responses when aggregated. Simulations are composed of autonomous agents that interact with other agents and the environment according to rules (e.g., Billari et al. 2006). Simulations are made, allowing agents to interact, and emergent responses are sought (i.e., formally, an aggregate response not obvious from the constituent parts; less formally, something that is unforeseen, unpredictable, and interesting). Rather than employing deductive or inductive approaches, an abductive approach is used to explore reasonable hypotheses that may explain a suite of observations (e.g., Griffin 2006; Lorenz 2009). These ideas give context to Epstein's quote describing generative social science and the usefulness of agent-based simulation, "if you didn't grow it, you didn't explain its emergence" (Epstein 1999:43). Being able to grow a pattern of interest and visualize the interactions of agents on a computer screen provides supporting evidence that the rules of interaction embedded in the model are good candidates to represent real interactions.

The rules describing interactions are hypotheses, and analysts use methods such as scenario analyses, a structured form of in silico experimentation (Peck 2004) in discovery. Different rules may be enabled or disabled in simulations representing different hypotheses of interaction, and the emergent patterns compared to observed patterns to judge the suitability of the competing hypotheses (Grimm and Railback 2006). Alternatively, scenarios may be used to address "what if" questions, where rules on assessed simulation models are varied to represent future conditions, different responses, or changes in policy or management (e.g., Boone et al. 2011).

The bottom-up approach of ABM that focuses on simulations of individuals has several benefits and costs when compared to top-down analytical approaches. (The following dichotomies refer to typical methods, and advanced methods can blur distinctions between the approaches.) Mathematical models such as the Mathusian population equation given yield precise solutions very quickly, and can 
be efficiently implemented, often with little data. In contrast, ABM models include stochastic components and the simulation of time passing that may slow the generation of results, and coding the models may be rapid or take significant time. Some ABMs use a great deal of data, but it is a misconception that the method requires more data than analytical approaches; some well-known and influential models require just one or a few parameters, such as Schelling's (1971) model of dynamic segregation, Axelrod's (1984) competitions using Prisoner's Dilemma, and Reynolds (1987) modeling of flocking using Boids, and all that it has spawned (see Macy and Willer 2002 for a review). Analytical models are highly stylized, to prevent problems from becoming mathematically intractable, whereas ABMs may be highly stylized or realistic. In contrast to the single scale of population models, results from ABM analyses are inherently multi-scale, in that analyses may be reported at the scale of agents, or any aggregate of interest. For example, some grand simulation of individuals across a broad region may report results for those individuals, summaries of households composed of those individuals, summarized by village, or for the entire population included in the simulation. The realistic approach used in many ABMs allows for a variety of scenarios to be addressed.

The top-down, population-based analytical approach implies that population members are identical and static. Treating each individual as identical can be a severe limitation in analytical approaches. Consider the simple biological example of forest stand growth from seedlings. Treating each seedling the same as the rest implies that through time the seedlings will mature at the same pace and a uniform forest will grow. In practice this is not the case. Variations between individuals cause some trees to shade others, and to grow more rapidly, yielding a more realistic result of a forest with diverse size classes. In ABM, variation between individuals is easily incorporated, and interactions between individuals with different initial attributes, such as body masses or livestock holdings, can yield more realistic results (Huston et al. 1988). This is why some social scientists have embraced the ABM approach, as some of the variability seen in the real world can be captured in these types of models. Examples where variation between individuals may be important are numerous in social settings, such as in economics, land use and tenure, altruism, and risk analyses. Here we have focused upon variation intrinsic to individuals as they are initialized, but in an ABM, agents that may be initialized identically each has its own experiences that yields differences in individuals, making results path dependent.

In contrast to static members of populations in analytical approaches, ABM can represent adaptation, learning, and evolution in agents. This makes ABM well suited to represent the complex and adaptive coupled systems that are a focus of current sustainability research. The rules used to control decision making may reflect adaptation. For example, in our work livestock owners may move their animals to more distant areas in drought conditions. Local interactions between agents make learning from neighbors straightforward, and imparting agents with different forms of memory is possible. Given a group of neighbors contacted by a given agent, that agent may ask if any member of the group is doing better in some objective way than the agent, and if so, adopt the practices of the neighbor. For example, a farmer 
in a valley may observe harvests by her neighbors, and if one of their harvests exceeds her own, adopt those cropping practices (see the example below of Lansing and Kremer 1993). Genetic algorithms, evolutionary programming, and other evolutionary computation techniques evolve adaptations using a framework adopted from biology. Agents with a given set of attributes perform better on some objective function than others in the group, and produce offspring that have related but mutated sets of attributes. Through selection, agents evolve to be well adapted to local conditions. Biological examples include Boone et al. (2006) and Boone (2010). Human evolutionary examples are given in Barton et al. (2011) and Barton and Riel-Salvatore (2012).

An important use of ABMs is in communication with audiences. Imagine a traffic modeler explaining to a lay audience about the number of vehicles that may be supported on a given road. The presenter may show a formula that describes maximum traffic flow, $q^{*}$ (from Malone et al. 2001) : $q^{*}=\left(\beta+2 \gamma^{1 / 2} L^{1 / 2}\right)^{-1}$, where $\beta$ is the reaction time of drivers, $\gamma$ is the reciprocal of twice the maximum average deceleration of a following vehicle, and $L$ is vehicle length, although the details are not relevant here. Alternatively, the presenter may show output from an ABM, where vehicles are moving along the road in reasonable ways, jams develop and clear, and vehicle densities may be reported directly (Fig. 9.1). Efforts have different purposes, of course, but in general, audiences identify with the visual nature of ABM output. People identify with agents in models and readily anthropomorphize; they themselves are individuals experienced in interactions with other individuals and environments.

Perhaps most important is the ability of agent-based modeling to integrate disciplines (Axelrod 2006). Almost by its nature, simulating complex system attributes involves interdisciplinary teams. Such a team may include a hydrologist, ecologists specializing in primary and secondary production, anthropologists and an economist, plus programmers and other specialists in technology. As the team creates rules that define interactions between the agents and the ways they interact with the environment, team members must break down their high level understanding of the causes of behaviors into something that may be represented logically. The rules must be conveyed to the technical team members with sufficient mutual understanding to allow them to be represented in computer code. The team must develop a common language and understanding. But beyond that, " $[\mathrm{t}]$ he creation of a model forces the articulation of any number of individual design decisions, and thoughtfully done, each can be a starting point for new understanding." (Johnston et al. 2007:82). Identifying commonalities between disciplines is particularly rewarding (Axelrod 2006). Some bodies of theory are applicable to diverse fields, such as theories that touch upon acquiring resources (e.g., with ties to economics, anthropology, animal foraging), altruism and cooperation (e.g., ethology, interpersonal relationships), issues of carrying capacity (e.g., grazers, hunters, members in markets), Tragedy of the Commons (Hardin 1968) or lack thereof (e.g., grazing dynamics, ocean fisheries management, group dynamics). Discussing these commonalities can strengthen a team.

In summary, agent-based modeling is a useful approach when: interactions between individuals and the environment are a focus; a model is complex with many interactions; non-linear relationships are important; variability between individuals 


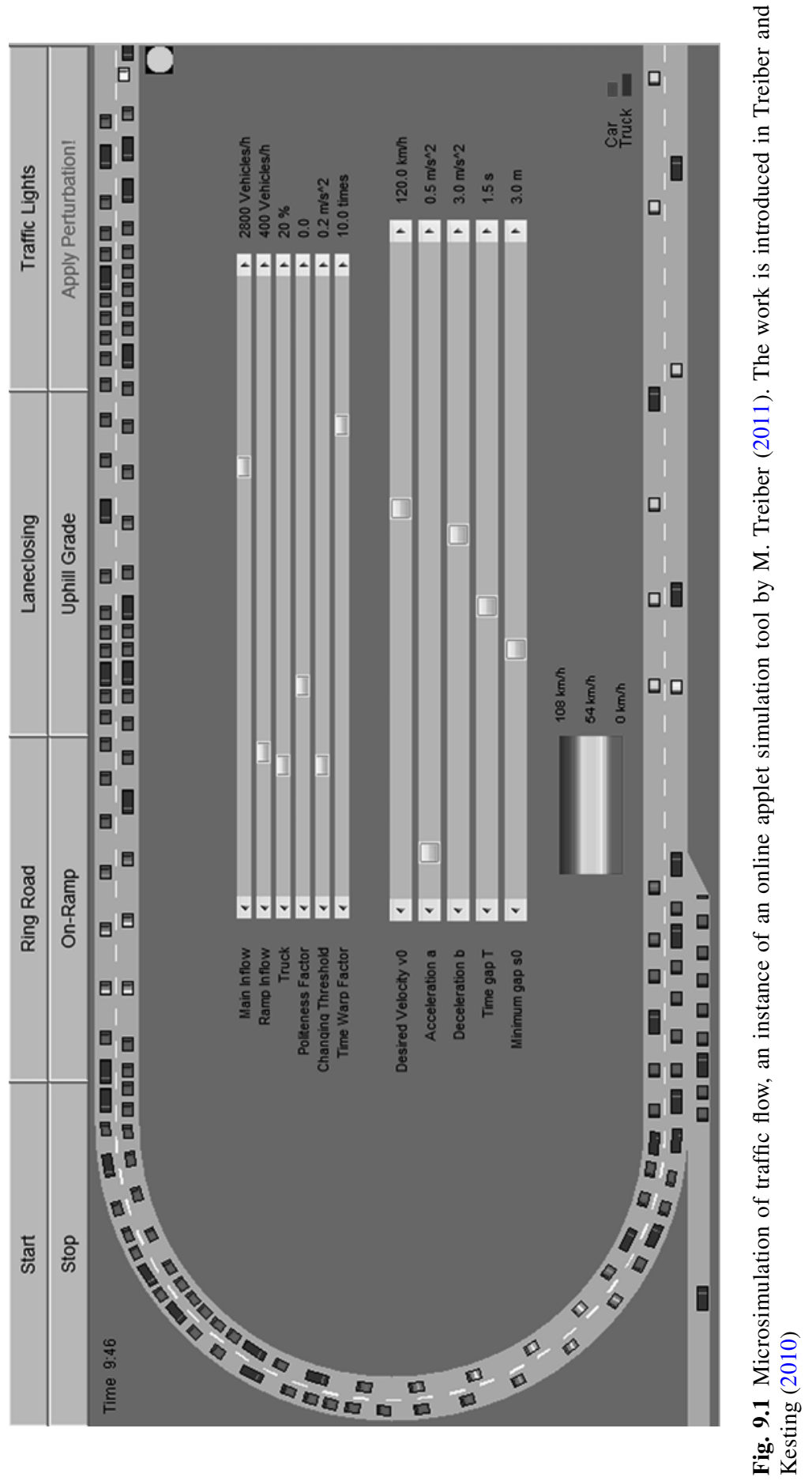


is of interest; randomness and path dependency are relevant; restrictive assumptions are to be minimized; and visualization and understanding by stakeholders is an objective. We have provided a high-level overview of the utility of agent-based modeling. Some aspects of constructing agent-based models have been cited, but more detailed reviews of techniques (e.g., Kraus 1997; Gilbert and Terna 2000; Berry et al. 2002; Bonabeau 2002; Ramanath and Gilbert 2004; Goldstone and Janssen 2005; Grimm et al. 2005; Janssen and Ostrom 2006; Aumann 2007; Railsback and Grimm 2011), tools (Wilensky 2001; Gilbert and Bankes 2002; Railsback et al. 2006; Nikolai and Gregory 2009; Railsback and Grimm 2011), assessment pathways, a critically important aspect of simulation (Grimm et al. 2005; Wilensky and Rand 2007; Gilbert 2008), and comments (Bankes 2002; Richiardi et al. 2006) are available to those constructing models. Example models and other resources are available from the Network for Computational Modeling for SocioEcological Science (CoMSES Net, at http://www.openabm.org/).

\subsection{Examples}

Our examples are selected to highlight different aspects of integrating social and ecological information, using examples from our work where applicable and a classic example in agent-based modeling that demonstrates several aspects of interest here.

\subsubsection{Integrated Assessments with SAVANNA and DECUMA}

The ecosystem modeling tool we have used the longest in integrated assessments is Savanna. Indeed, M. Coughenour of Colorado State University began developing SAVANNA while working on one of the first large-scale projects to consider humans and their environment in an integrated way, the South Turkana Ecosystem Project of the 1980s (Ellis et al. 1993; Little and Leslie 1999). In the late 1990s, the Savanna model was the integrative tool we used to bring together data collection and analysis efforts that included anthropological surveys, ecological field sampling, literature review, and spatial data (Galvin et al. 2006). SAVANNA is a spatially-explicit, processbased model of ecosystem change. Landscapes are divided into a series of square cells, with geographic data layers informing the model of cell attributes. The model represents plant functional groups, such as palatable grasses, dwarf unpalatable shrubs, or acacia trees. Plant functional groups compete for water, nutrients, light, and space, based on cell attributes such as soil type, weather data that includes temperature and precipitation, plus a suite of parameter files that describe or control plant growth and competition. At each time-step, plants may produce seed, germinate, grow, outcompete other functional groups and gain ground cover, or be outcompeted by other plants and die. Wildlife and livestock are represented in the model as 
populations that feed on the plants to gain energy, and expend energy through basal metabolism, movement, thermal regulation, plus reproduction including gestation and lactation. Net energy increase goes to weight gain, and an energy deficit to weight loss. Body weight is compared to an expected standard to yield a condition index that affects birth, death, and other vital rates. The model uses a weekly time-step, where the state of the system is simulated once each week, and produces spatial and temporal output once per month.

The use of a comprehensive model such as Savanna is time intensive. That said, the trade-off is its great flexibility in addressing scenarios. We used SAvANNA in scenario analyses to address 15 management options available to the conservators of Ngorongoro Conservation Area (Boone et al. 2002). We explored effects of drought, changes in livestock access and stocking, the expansion of cultivation and its effect on the system, changes in veterinary care, changes in water supplies, and human population growth. In general these scenarios were represented by making relatively simple changes to the files used by SAVANNA. For example, to represent changes in water supply that affect livestock and wildlife distribution, water sources were added or removed in a GIS and distance-to-water surfaces used in the model were recalculated. To represent improved veterinary practices, the survival of livestock was increased slightly. We have used the model to help extend the utility of climate forecasts to South African livestock owners (Boone et al. 2004), by itself and as linked to a mathematical linear programming model that provided measures of economic benefit to livestock owners (Thornton et al. 2004). In recent years we have used the integrated system to explore effects of fragmentation on livestock, wildlife, and people (e.g., Boone et al. 2005; Boone 2007; Hobbs et al. 2008).

Early in our work, P. Thornton of the International Livestock Research Institute, Nairobi, led an effort to extend our integrated modeling of areas to include the livestock owners and their households. He created the PHEWS model (Pastoral Household Economic Welfare Simulator) as a population-based representation of Maasai households, which is tightly joined to the SAvanna model (Thornton et al. 2003, 2006). That model represented decision making by household owners using a series of ordered rules, applied to a modest number (9-24) of groups of households, such as poor, medium, and rich business owners with livestock. The flows of food energy and currency were tracked in the model.

The population-based nature of PHEWS prevented us from simulating individual households who own their own livestock herds. It follows that we could not have local ecosystem services influence the decision making of household owners - local conditions cannot be defined for populations of hundreds of households. We converted the PHEWS model into an agent-based representation called DECUMA (DECision-making Under Conditions of Uncertainty for Modeled Agents, and also the name of a Roman fate that influences the length of life). In DECUMA, individual households are represented as occurring at specific locations on earth, and they own specific livestock herds. When linked to SAVANNA, that allows us to have local ecosystem services influence the decision making of pastoral people, and to have their decisions influence ecosystem services. Boone et al. (2011) describes the DECUMA model and linkage with SAVANNA in detail. 
DECUMA has been applied in Kajiado District, southwest Kenya, and applications are ongoing in Samburu, Kenya, as well as Mali and Tibet. The Malian application provides an example of the usefulness of making tools used in integration portable. In that work, led by N. Hanan of South Dakota State University, we are exploring changes in the hydrology of lakes, the roles that pastoral people have had in those changes, and the benefits to them. A hydrological model (SWAT; Gassman et al. 2007) is being linked to the ecosystem model called ACE (African Carbon Exchange), which in turn is being linked to DECUMA. By programmatically isolating the materials DECUMA requires from an ecosystem model (see Boone et al. 2011 for details), we can relatively easily link the model with any ecosystem simulation tool that can provide the needed information (e.g., forage availability and forage acquired by animals).

Our ongoing analyses in Samburu, Kenya demonstrates this kind of integrated modeling. C. Lesorogol of Washington University, St. Louis, Missouri has gathered in-depth anthropological data for two study sites in southwest Samburu District, Mbaringon and Siambu. The sites differ in ecological settings, with Mbaringon at lower elevation and with less rainfall, for example. But the main difference of anthropological interest is that Siambu is subdivided, and Mbaringon remains communal lands (although somewhat fragmented). In the 1970s residents within some districts in Kenya began to subdivide into individually owned parcels. In Siambu, the land was divided into 240 small individually owned parcels. We are also investigating changes in Samburu norms, where the sense of reciprocity and sharing is less important in young peoples' lives.

Our integrated assessments are driven by both theoretical questions and by questions put forth by stakeholders (Reid et al. 2009). The eight scenarios (numbered below) we are addressing in Samburu reflect this, and highlight the flexibility of using comprehensive simulation tools such as SAVANNA and DECUMA. Central to our work are questions of subdivision and its effects. We are simulating sedentarizing people and their animals on individually owned parcels, and the effects of that on livelihoods (1). Another scenario asks about the influence of commercial cropping in Siambu and fence building in Mbaringon, and the effects of loss of access has on livestock (2). These types of scenarios are represented in the modeling system by altering spatial surfaces or agent behaviors so as to prevent animals from leaving home parcels or from using areas that are inaccessible. We describe a diversity of scenarios to demonstrate the utility of integrated modeling but discuss one (number 8) in more detail here.

Both Siambu and Mbaringon are grazing refuges for herders outside those areas. When drought conditions hold in other areas of Samburu, herders move their animals into these areas. In a scenario, we are adding additional livestock to each area, and summarizing effects on the resident animals (3). Plains zebras (Equus quagga) and occasionally Grevy's zebras (Equus grevyi) are joined by various antelopes in the Mbaringon study site. We will vary the numbers of wildlife by a factor of four in scenarios, with and without tourism benefits to local people, to judge effects on livestock numbers and household livelihoods (4). Livestock sales are increased in simulations, above the observed number of sales that is typical (5). This is an 
example of a scenario that Samburu residents asked us to include, given their interest in intensifying their livestock management. A program is in place now, led by C. Lesorogol, to introduce enhanced and highly productive goat breeds into Siambu. In a scenario, attributes of goats are modified to represent mixed herds of local and enhanced breeds, and effects on livelihoods judged (6). Residents asked us to explore the implications of improved crop yields on livelihoods (7). This scenario addresses a variety of management options, streamlined so as to be amenable to simulation with our tools. For example, land owners struggle to decide whether increased production from high-yield seed stocks outweigh their increased costs, whether to invest in chemical fertilizers (very few do in the region), investing in water projects for irrigation, and the usefulness versus costs of drought tolerant seeds.

The last scenario (8) compares the costs and benefits of increasing or decreasing veterinary care for livestock. Residents seek to balance the money they spend on veterinary care with the benefits they receive through improved livestock health and survival. We used an application of SAVANNA and DECUMA to Mbaringon to address this scenario. These preliminary results report outcomes from three simulations (baseline, increased livestock survival by $3 \%$, decreased by $3 \%$ ); in practice we do 20 or more simulations of each type to yield error estimates. Such a seemingly small change in survival for large herbivores can have dramatic impacts on population dynamics. In this example, Fig. 9.2 (top) shows about a 1 tropical livestock unit (TLUs) increase for each adult equivalent (AE). These metrics are methods of standardizing livestock of different species (e.g., a cattle is 1 TLU, and a sheep or goat is 0.1 TLU) and humans of different ages and sexes (e.g., an adult male is $1 \mathrm{AE}$, and a child 6-12 years old is 0.85 AE) (Boone et al. 2011). Figure 9.2 (bottom) demonstrates one of the many linkages within the SAVANNA-DECUMA integrated system. The average proportion of households' diets composed of supplemental food decreases when more funds are spent on veterinary care. This must be weighed against the costs of the improved care.

\subsubsection{Balinese Water Temple Networks}

We draw on a time-honored agent-based simulation study to demonstrate two aspects helpful to understanding how integrated modeling may address resilience, simulating adaptation and network modeling. Lansing and Kremer (1993) describe an agricultural system in Bali that is dependent upon irrigation fed by rivers carrying rainfall runoff. Blocks of terraces are planted in rice. A tension with three main dimensions exists within the system involving a balance between yield, water use, and pest damage. Individuals seek to maximize yields, but if everyone plants each year, there would likely be insufficient precipitation to irrigate. Also, if farmers planted each block, pest populations can expand and severely reduce yields. In the 1970s, crop management was disorganized, all blocks were planted, plants were likely water-stressed, and pests reduced yields by up to $50 \%$, far greater losses than seen in the 1990s. Farmers are organized into groups called subaks, which 
Fig. 9.2 Effects based on preliminary results of increasing or decreasing veterinary care on livestock in Mbaringon, Samburu District, Kenya. The scenario included increasing or decreasing livestock survival by $3 \%$ reflecting changes in care. Increasing veterinary care increased numbers of livestock per person (top, hashed line) and reduced the need for supplemental foods (bottom, hashed line)
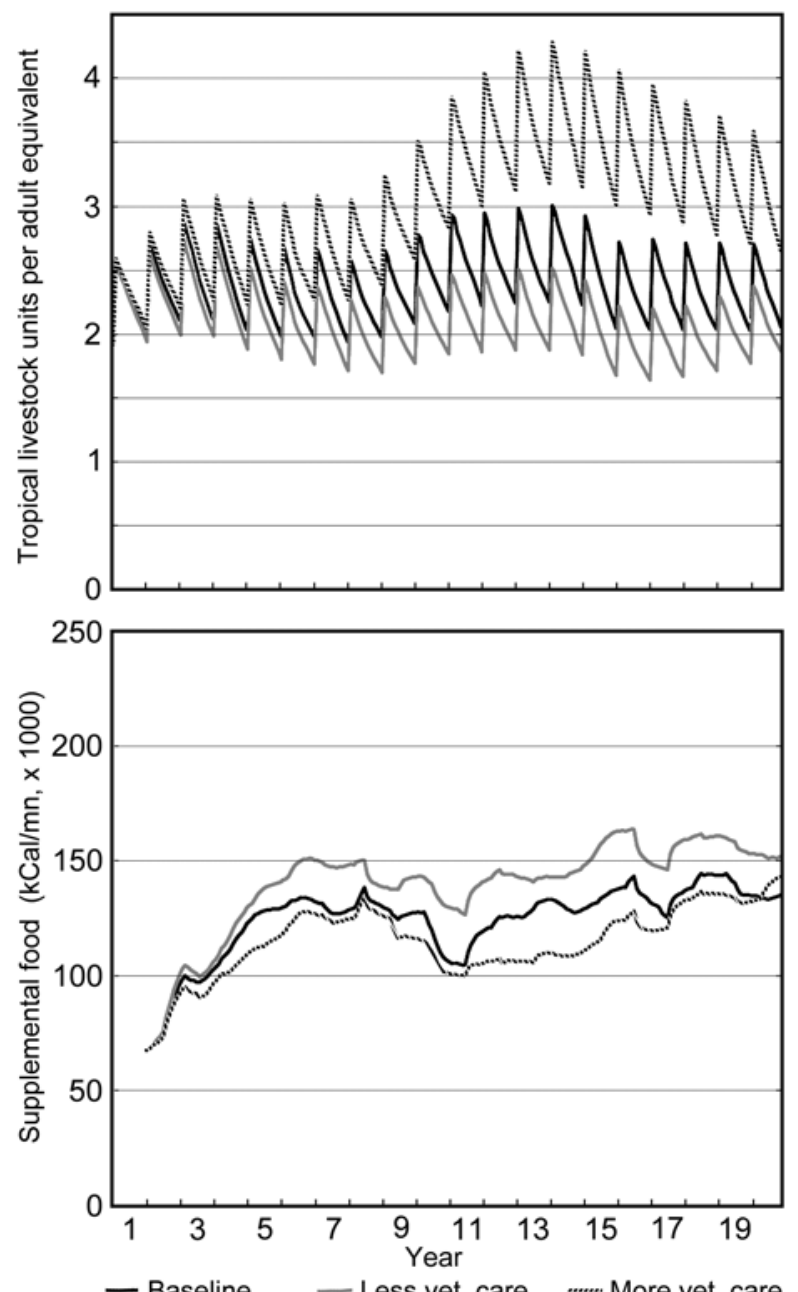

coordinate to balance whether blocks are planted or in fallow. An intricate network of temples and shrines is present that promotes coordination. Whether crop yield would be highest if coordinated at very local scales, at the scale of the entire region, or at a scale similar to that of the temples was of interest to Lansing and Kremer (1993). Lansing and Kremer (1993 and cites therein) built an agent-based model of 172 subaks, with each containing information about the basin in which it occurs, where water is drawn from, and other information. The spatial connectedness of subaks was represented as a network, such that neighbors were aware of the management and crop performance of their neighbors. The simulation included estimates of rainfall, irrigation demand, rice growth stage, and pest load. Harvests varied in response to water stress and pest load. In early simulations, the authors 
found that subak-scale coordination reduced yields due to pests. Coordination across the region caused plants to be water-stressed. The coordination that was best was at a scale on par with that of temples and shrines that are located within subaks. But the authors continued to question how temple networks would form, and how they may coordinate cropping. Lansing and Kremer (1993) incorporated a learning component into their network. Subaks residents looked to neighboring subaks, and if the management system used produced greater yields, it was adopted. After initializing crop management to randomly selected systems, within a decade of simulated learning crop yields almost doubled. This clear example of simulating adaptation, and specifically irrigation within the Bali Temples system, has spawned expanded analyses (e.g., Janssen 2007; Lansing et al. 2009).

\subsubsection{Wet Season Versus Dry Season Livestock Dispersal}

An example of the utility of a theoretical or stylized simulation relates to changes in livestock dispersal patterns by Maasai herders in Kajiado, Kenya. Forty years ago, herders moved their animals in a pattern echoing the movements of wildlife of the Amboseli Basin (Worden 2007). In the wet season, livestock were grazed broadly, using ephemeral water sources and eating forage distant from permanent water. As water became limiting, livestock herders moved their animals closer to permanent water sources. During the dry season, herds grazed areas around the permanent water sources. This pattern may be summarized as wet season dispersal of livestock.

It is reasonable to think that animals confined to a relatively small area at the height of resource shortages - the dry season - may reduce forage acquisition and livestock populations. In the 1980s, Maasai adopted a cultural and institutional system where elders imposed a wet season dispersal pattern for livestock (BurnSilver 2007). Herders graze their animals in the areas around permanent water sources (which tend to be near their permanent residences) during the wet season. Areas distant from permanent water are kept as grazing reserves. As the landscape dries and forage is depleted, elders open neighboring areas to grazing, in what is termed a "staged" approach (BurnSilver 2007). Herders graze animals there until forage is depleted, and another stage is opened. By the height of the dry season, higher elevation grazing reserves are being used, and animals are being grazed for 2-3 days, then walked back to permanent water to drink. They then return to the reserve to graze for 2-3 days, and the cycle repeats until new rains arrive.

We sought to assess the utility of wet season versus dry season dispersal for livestock, and chose a stylized ecosystem representation in NetLogo 5.0 (Northwestern University, Evanston, Illinois). Major aspects of the model are introduced here, with minor points omitted for brevity; the full model has been placed in the Community section of the NetLogo web site (http://ccl.northwestern.edu/netlogo/). A grassland was represented by a grid of patches $41 \times 41$, with each pixel approximating $1 \mathrm{~km}^{2}$. The grid represented a torus to avoid edge effects, such that an animal moving off one edge of the grid appeared on the opposite edge. In each landscape cell, 
we implemented a forage growth model following Fryxell et al. (2005). That source provides formula that link stochastic precipitation with rates of growth of grasses. Rainfall included a $25 \%$ inter-annual coefficient of variation, with precipitation distributed evenly throughout the growing season. A modified logistic growth curve represented forage production through time based on precipitation. Animals gained weight from the forage they ate, lost weight if there was insufficient forage, and reproduced at a rate related to their body condition.

A variable number of wells were distributed randomly throughout the grassland simulated. Animals were compelled to return to wells to drink every 3 days; if a measure of thirst for an animal exceeded a threshold (i.e., 7.5 days in this stylized simulations), the animal died. A switch on the simulation interface (Fig. 9.3) allowed the model to adopt a dry season or a wet season dispersal. We simulated dry season and wet season dispersal of livestock, and varied the number of wells on the landscape from 1 to 10 . For each combination, we used 30 simulations to yield standard error estimates. Based on these stylized simulations, the utility of the newer dry season dispersal pattern to pastoralists may be questioned (Fig. 9.4). The usefulness of storing vegetation in areas distant from water sources for use in the dry season is outweighed by the ability of animals to graze more freely during the wet season. These results are not definitive, given the stylized application used, but they do suggest that more detailed follow-up analyses would be helpful and that field data be collected.

\subsection{Summary and Conclusions}

Models by their nature are incomplete representations of the realities they seek to describe. Some are caricatures of reality, some seek to emulate real-world higherlevel patterns, and some seek quantitative agreement with patterns through space and time (Axtell and Epstein 1994). The correctness and utility of a model should be considered in the context of its purpose. A purpose becoming more common is to represent ecological and social systems, and the linkages in between. In general, ecological modeling is more advanced than modeling social systems - there are many opportunities for advancing knowledge and methods in social simulation. Agent-based modeling has been useful in representing human decision making. The method is highly flexible, and able to incorporate individual variation and path dependencies. If-then structures and the parameters used in them become hypotheses that may be tested, in direct analogy to field experiments. Linked ecosystem and agent-based models allow changes in ecosystem services to be reflected in the behaviors that people exhibit. In turn, the behaviors that people make can alter the services an ecosystem provides (Bonabeau 2002). For example, changes in forage availability may be simulated in an ecosystem model, which influences the ways in which people distribute their livestock, which in turn affects forage availability in later periods. In an example we demonstrate an integrated model of two areas in Samburu, Kenya. That is an example where we seek to be in quantitative 


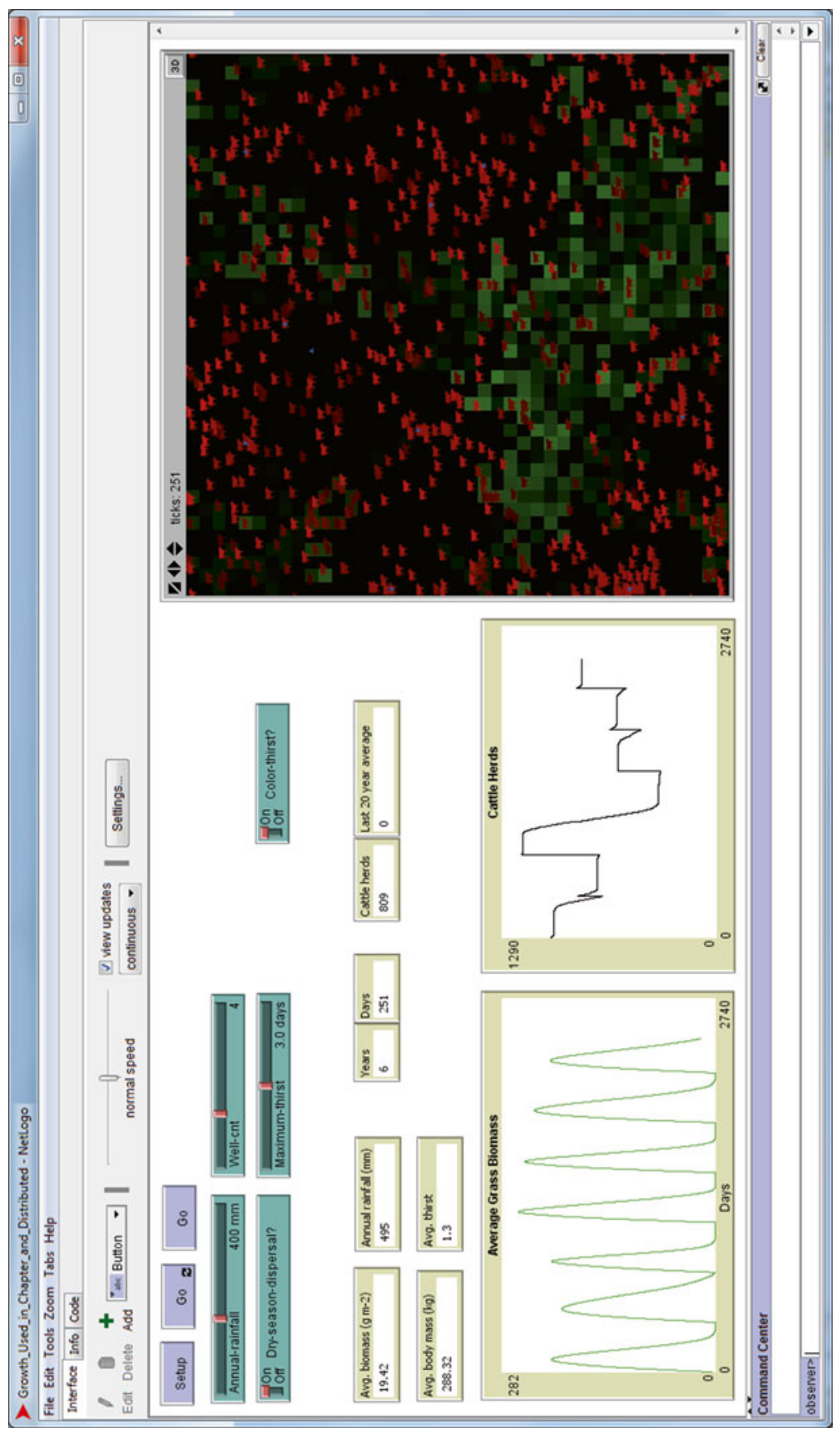

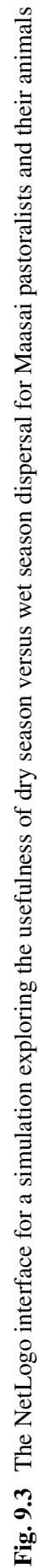


Fig. 9.4 The number of cattle herds that may be supported on a stylized landscape with different numbers of randomly distributed water wells, and either a pattern of wet season dispersal during grazing (solid line) or dry season dispersal (dotted line). Standard error bars are shown

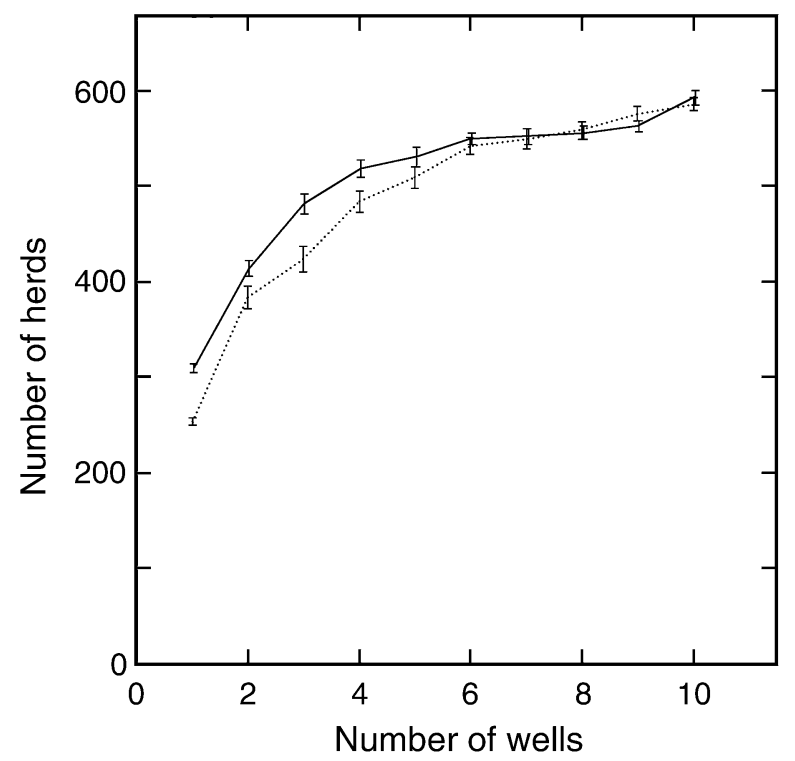

agreement with the observed system. It also demonstrates the flexibility (and challenge) that comes with using comprehensive tools. An example from the literature depicts agents learning and adapting, and the means in which agents may form networks where information is shared. Lastly, we demonstrate a stylized simulation of livestock dispersal patterns in grazing lands of Kenya.

Our emphasis on agent-based modeling should not suggest that its use is the only way to integrate across the natural and social sciences. As always, the questions to be addressed dictate the approach and tools to be used. Some other useful pathways have been cited here, such as participatory mapping and other participatory methods, which allow for the inclusion of indigenous knowledge in research. Other more mainstream means of modeling may be used in integration, such as empirical methods or systems modeling approaches. Spatial analyses using geographic information systems help bridge social and natural sciences, for example by providing geographic context to household survey results (e.g., Boone et al. 2000). Remote sensing allows effects of human activities to be placed in the context of broad spatial scales, with sampling through space and time and without undo expense. Land use change quantified using remotely sensed data is now a well-developed field. Planning and the use of scenario analyses allow interdisciplinary teams to integrate aspects of their work. For example, questions about changes in social systems may be framed by scenarios regarding changing climate or changes in the services that an ecosystem provides.

Though tools and pathways of integration are increasing, the ability to integrate across the sciences it is not without challenges. There remain issues of scale, including mismatched social-organizational scales, such as comparing administrative boundaries with landscape scales in which ecological flows such as water, wildlife and soil nutrients occur. There are scales of drivers and impacts that go between the local, regional, national, and to the global scale, such as climate change, land use and other 
policies, market influences and others that are difficult and sometimes intractable. There are also challenges associated with human populations that are important but sometimes difficult to include in integration efforts and include information on equity, gender, justice, class, ethnicity, power and history. These are important because they determine winner and losers of social ecological inquiry and they are central to realizing change in practice on the ground.

There are factors that help to integrate social sciences and natural resources. These include new theories and methods. Theories of political ecology (cf Robbins 2012), resilience and social-ecological systems (cf Folke 2006), and common property (cf Ostrom 2002) as examples can help us ask multi-scale questions, incorporate socially and culturally structured relations into the research (such as gendered decision-making roles or ethnicity/class and degraded or resource poor landscapes) and iteratively linked human decisions to environmental outcomes and vice versa. This inclusion of complexity calls for mixed methods; we are no longer tied to mainstream disciplinary methods but rather a set of mixed methods may be used to answer the problems at hand. These include Photovoice, videography, qualitative unstructured and semi-structured interviews, focus groups, workshops, participatory modeling, formal surveys and social network analysis. By coupling these methods with the ecological and geographical methods and tools mentioned above, including agent based modeling, we can continue to develop solutions to timely and important societal and environmental problems.

Acknowledgements Our thanks to our many colleagues who have participated in the research examples we have cited. Support for preparing this chapter was provided by US National Science Foundation grants DEB-1010465, BCS-0822752, and DEB-0919383.

Open Access This chapter is distributed under the terms of the Creative Commons Attribution Noncommercial License, which permits any noncommercial use, distribution, and reproduction in any medium, provided the original author(s) and source are credited.

\section{References}

An, L., \& López-Carr, D. (2011). Understanding human decisions in coupled natural and human systems. Ecological Modelling, 229, 1-4.

Aumann, C. A. (2007). A methodology for developing simulation models of complex systems. Ecological Modelling, 202, 385-396.

Axelrod, R. (1984). The evolution of cooperation. New York: Basic Books.

Axelrod, R. (2006). Agent-based modeling as a bridge between disciplines. In L. Tesfatsion \& K. L. Judd (Eds.), Handbook of computational economics (Agent-based computational economics, Vol. 2, pp. 1565-1584). Amsterdam: Elsevier.

Axtell, R. L., \& Epstein, J. M. (1994). Agent-based modeling: Understanding our creations. The Bulletin of the Santa Fe Institute, 9(2), 28-32.

Bankes, S. C. (2002). Agent-based modeling: A revolution? Proceedings of the National Academy of Science, 99, 7199-7200.

Barton, C. M., \& Riel-Salvatore, J. (2012). Agents of change: modeling biocultural evolution in upper Pleistocene western Eurasia. Advances in Complex Systems, 15(1\&2), 1150003. 
Barton, C. M., Riel-Salvatore, J., Anderies, J. M., \& Popescu, G. (2011). Modeling human ecodynamics and biocultural interactions in the Late Pleistocene of western Eurasia. Human Ecology, $39,705-725$.

Becu, N., Neef, A., Schreinemachers, P., \& Sangkapitux, C. (2008). Participatory computer simulation to support collective decision-making: Potential and limits of stakeholder involvement. Land Use Policy, 25, 498-509.

Berkes, F. (1999). Sacred ecology. New York: Taylor and Francis.

Berkes, F., Colding, J., \& Folke, C. (2003). Navigating social-ecological systems. Building resilience for complexity and change. Cambridge, MA: Cambridge University Press.

Berry, B. J., Kiel, L. D., \& Elliott, E. (2002). Adaptive agents, intelligence, and emergent human organization: capturing complexity through agent-based modeling. Proceedings of the National Academy of Science, 99, 7187-7188.

Beschta, R. L., Bilby, R. E., Brown, G. W., Holtby, L. B., \& Hofstra, T. D. (1987). Stream temperature and aquatic habitat: Fisheries and forestry interactions. In E. O. Salo \& T. W. Cundy (Eds.), Streamside management: Forestry and fishery interactions (pp. 191-232). Seattle: University of Washington, Institute of Forest Resources, Contribution No. 57.

Billari, F. C., Fent, T., Prskawetz, A., \& Scheffran, J. (2006). Agent-based computation modeling: An introduction. In F. C. Billari, T. Fent, A. Prskawetz, \& J. Scheffran (Eds.), Agent-based computational modeling, contributions to economics (pp. 1-16). Heidelberg: Physica-Verlag.

Bonabeau, E. (2002). Agent-based modeling: Methods and techniques for simulating human systems. Proceedings of the National Academy of Science, 99(10), 7280-7287.

Boone, R. B. (2007). Effects of fragmentation on cattle in African savannas under variable precipitation. Landscape Ecology, 22(9), 1355-1369.

Boone, R. B. (2010). Simulating species richness using agents with evolving niches, with an example of Galapagos plants. International Journal of Ecology, id150606. doi:10.1155/2010/150606

Boone, R. B., Galvin, K. A., Smith, N. M., \& Lynn, S. J. (2000). Generalizing El Niño effects upon Maasai livestock using hierarchical clusters of vegetation patterns. Photogrammetric Engineering and Remote Sensing, 66, 737-744.

Boone, R. B., Coughenour, M. B., Galvin, K. A., \& Ellis, J. E. (2002). Addressing management questions for Ngorongoro Conservation Area using the Savanna Modeling System. African Journal of Ecology, 40, 138-150.

Boone, R. B., Galvin, K. A., Coughenour, M. B., Hudson, J. W., Weisberg, P. J., Vogel, C. H., \& Ellis, J. E. (2004). Ecosystem modeling adds value to a South African climate forecast. Climatic Change, 64(3), 317-340.

Boone, R. B., BurnSilver, S. B., Thornton, P. K., Worden, J. S., \& Galvin, K. A. (2005). Quantifying declines in livestock due to subdivision. Rangeland Ecology \& Management, 58, 523-532.

Boone, R. B., Thirgood, S. J., \& Hopcraft, J. G. C. (2006). Serengeti wildebeest migratory patterns modeled from rainfall and new vegetation growth. Ecology, 87(8), 1987-1994.

Boone, R. B., Galvin, K. A., BurnSilver, S. B., Thornton, P. K., Ojima, D. S., \& Jawson, J. R. (2011). Using coupled simulation models to link pastoral decision making and ecosystem services. Ecology and Society, 16(2), 6 [online]. URL: http://www.ecologyandsociety.org/ vol16/iss2/art6/

Boyd, R., \& Richerson, P. J. (2005). The origin and evolution of cultures. Oxford: Oxford University Press.

Brenner, T. (Ed.). (1999). Computational techniques for modeling learning in economics. Norwell: Kluwer Academic.

Brosius, J. P. (1997). Endangered forest, endangered people: Environmentalist representations of indigenous knowledge. Human Ecology, 25, 47-69.

BurnSilver, S. B. (2007). Settlement pattern and fragmentation in Maasailand: implications for pastoral mobility, drought vulnerability, and wildlife conservation in an East African savanna. Dissertation submitted to the Graduate Degree Program in Ecology, Colorado State University, Fort Collins.

Camerer, C. F., Loewenstein, G., \& Rabin, M. (2003). Advances in behavioral economics. Princeton: Princeton University Press. 
Cangelosi, A., \& Parisi, D. (Eds.). (2001). Simulating the evolution of language. Dordrecht: Springer.

Carpenter, S. R., Armbrust, E. V., Arzberger, P. W., Chapin, F. S., III, Elser, J. J., Hackett, E. J., Ives, A. R., Kareiva, P. M., Leibold, M. A., Lundberg, P., Mangel, M., Merchant, N., Murdoch, W. W., Palmer, M. A., Peters, D. P. C., Pickett, S. T. A., Smith, K. K., Wall, D. H., \& Zimmerman, A. S. (2009). Accelerate synthesis in ecology and environmental sciences. BioScience, 59(8), 699-701.

Crumley, C. L. (Ed.). (1994). Historical ecology: Cultural knowledge and the changing landscapes. Santa Fe: School of American Research Press.

Ellis, J. E., Coughenour, M. B., \& Swift, D. M. (1993). Climate variability, ecosystem stability, and the implications for range and livestock development. In R. H. Behnke Jr., I. Scoones, \& C. Kerven (Eds.), Range ecology at disequilibrium: New models of natural variability and pastoral adaptation in African savannas (pp. 31-41). London: Overseas Development Institute.

Epstein, J. M. (1999). Agent-based computational models and generative social science. Complexity, 4, 41-60.

Epstein, J. M. (2008). Why model? Journal of Artificial Societies and Social Simulation, 11(4), 12. http://jasss.soc.surrey.ac.uk/11/4/12.html

Escobar, A. (1998) Whose knowledge, whose nature? Biodiversity, conservation and the political ecology of social movements. Journal of Political Ecology, 5(1). http://jpe.library.arizona.edu/ Volume5/Volume_5_1.html

Folke, C. (2006). The emergence of a perspective for social-ecological system analysis. Global Environmental Change: Human and Policy Dimensions, 16(3), 253-267.

Folke, C., Carpenter, S., Elmqvist, T., Gunderson, L., Holling, C. S., \& Walker, B. (2002). Resilience and sustainable development: building adaptive capacity in a world of transformations. AMBIO: A Journal of the Human Environment, 31(5), 437-440.

Fryxell, J. M., Wilmhurst, J. F., Sinclair, A. R. E., Haydon, D. T., Holt, R. D., \& Abrams, P. A. (2005). Landscape scale, heterogeneity, and the viability of Serengeti grazers. Ecology Letters, $8,328-335$.

Galvin, K. A., Thornton, P. K., Roque de Pinho, J., Sunderland, J., \& Boone, R. B. (2006). Integrated modeling and its potential for resolving conflicts between conservation and people in the rangelands of East Africa. Human Ecology, 34(2), 155-183.

Gassman, P. W., Reyes, M. R., Green, C. H., \& Arnold, J. G. (2007). The soil and water assessment tool: Historical development, applications, and future research directions. Transactions of the American Society of Agricultural and Biological Engineers, 50(4), 1211-1250.

Gaston, K. J., \& Blackburn, T. M. (2000). Pattern and process in macroecology. Oxford: Blackwell.

Gilbert, N. (2008). Agent-based models, Quantitative applications in social sciences (Issue 7, Part 153). Thousand Oaks: SAGE University Papers.

Gilbert, N., \& Bankes, S. (2002). Platforms and methods for agent-based modeling. Proceedings of the National Academy of Science, 99, 7197-7198.

Gilbert, N., \& Terna, P. (2000). How to build and use agent-based models in social science. Mind \& Society, 1(1), 57-72.

Goldstone, R. L., \& Janssen, M. A. (2005). Computational models of collective behavior. Trends in Cognitive Sciences, 9(9), 424-430.

Griffin, W. A. (2006). Agent-based modeling for the theoretical biologist. Biological Theory, 1(4), 404-409.

Grimm, V. (1999). Ten years of individual-based modeling in ecology: What have we learned and what could we learn in the future? Ecological Modelling, 115(1999), 129-148.

Grimm, V., \& Railback, S. F. (2006). Agent-based models in ecology: Patterns and alternative theories of adaptive behavior. In F. C. Billari, T. Fent, A. Prskawetz, \& J. Scheffran (Eds.), Agent-based computational modeling, contributions to economics (pp. 139-152). Heidelberg: Physica-Verlag.

Grimm, V., Revilla, E., Berger, U., Jeltsch, F., Mooij, W. M., Railsback, S. F., Thulke, H.-H., Weiner, J., Wiegand, T., \& DeAngelis, D. L. (2005). Pattern-oriented modeling of agent-based complex systems: Lessons from ecology. Science, 310, 987-991. 
Hardin, G. (1968). The tragedy of the commons. Science, 162, 1243-1248.

Hobbs, N. T., Galvin, K. A., Stokes, C. J., Lackett, J. M., Ash, A. J., Boone, R. B., Reid, R. S., \& Thornton, P. K. (2008). Fragmentation of rangelands: implications for humans, animals, and landscapes. Global Environmental Change, 18(4), 776-785.

Huston, M., DeAngelis, D., \& Post, W. (1988). New computer models unify ecological theory. BioScience, 38(10), 682-691.

Janssen, M. A. (2007). Coordination in irrigation systems: An analysis of the Lansing-Kremer model of Bali. Agricultural Systems, 93, 170-190.

Janssen, M. A., \& Ostrom, E. (2006). Empirically based, agent-based models. Ecology and Society, 11, 37 [online]. URL: http://www.ecologyandsociety.org/vol11/iss2/art37/

Johnston, E., Kim, Y., \& Ayyanger, M. (2007). Intended and unintended: The act of building agentbased models as a regular source of knowledge generation. Interdisciplinary Description of Complex Systems, 5(2), 81-91.

Kareiva, P., \& Andersen, M. (1988). Spatial aspects of species interactions: The wedding of models and experiments. In A. Hastings (Ed.), Community ecology (pp. 38-54). New York: Springer.

Kohler, T. A., \& Gumerman, G. J. (Eds.). (1999). Dynamics in human and primate societies: Agent-based modeling of social and spatial processes (Santa Fe Institute studies in the sciences of complexity). Oxford: Oxford University Press.

Kraus, S. (1997). Negotiation and cooperation in multi-agent environments. Artificial Intelligence, 94, 79-97.

Lansing, J. S., \& Kremer, J. N. (1993). Emergent properties of Balinese water temple networks: Coadaptation on a rugged fitness landscape. American Anthropologist, 95(1), 97-114.

Lansing, J. S., Cox, M. P., Downey, S. S., Janssen, M. A., \& Schoenfelder, J. W. (2009). A robust budding model of Balinese water temple networks. World Archaeology, 41(1), 112-133.

Leach, M., Rockström, J., Raskin, P., Scoones, I., Stirling, A. C., Smith, A., Thompson, J., Millstone, E., Ely, A., Around, E., Folke, C., \& Olsson, P. (2012). Transforming innovation for sustainability. Ecology and Society, 17(2), 11. http://dx.doi.org/10.5751/ES-04933-170211

Little, M. A., \& Leslie, P. W. (Eds.). (1999). Turkana herders of the dry savanna. Ecology and biobehavioral response of nomads to an uncertain environment. Oxford: Oxford University Press.

Liverman, D., Moran, E. F., Rindfuss, R. R., \& Stern, P. C. (1998). People and pixels. Linking remote sensing and social sciences. Washington, DC: National Academy Press.

Lorenz, T. (2009). Epistemological aspects of computer simulation in the social sciences. Lecture Notes in Computer Science, 5466, 141-152.

Macy, M. W., \& Willer, R. (2002). From factors to actors: Computational sociology and agentbased modeling. Annual Review of Sociology, 28, 143-166.

Malone, S. W., Miller, C. A., \& Neill, D. B. (2001). Traffic flow models and the evacuation problem. UMAP Journal, 22, 271-290.

MEA (Millennium Ecosystem Assessment). (2005). Ecosystems and human well-being: Synthesis. Washington, DC: Island Press.

Moran, E. F. (2008). Human adaptability. Boulder: Westview Press.

Nikolai, C., \& Gregory, M. (2009). Tools of the trade: a survey of various agent based modeling platforms. Journal of Artificial Societies and Social Simulation, 12(2), 2. http://jasss.soc.surrey. ac.uk/12/2/2.html

Orlove, B. S. (1980). Ecological anthropology. Annual Review of Anthropology, 9, 235-273.

Ostrom, E. (2002). The drama of the commons. Washington, DC: National Academy Press.

Peck, S. L. (2004). Simulation as experiment: A philosophical reassessment for biological modeling. Trends in Ecology and Evolution, 19(10), 530-534.

Peet, R., \& Watts, M. (1996). Liberation ecologies: Environment, development, social movements. London: Routledge.

Railsback, S. F., \& Grimm, V. (2011). Agent-based and individual-based modeling: A practical introduction. Princeton: Princeton University Press.

Railsback, S. F., Lytinen, S. L., \& Jackson, S. K. (2006). Agent-based simulation platforms: Review and development recommendations. Simulation, 82(9), 609-623. 
Ramanath, A. M., \& Gilbert, N. (2004). The design of participatory agent-based social simulations. Journal of Artificial Societies and Social Simulation, 7(4), 1 [online]. http://jass.soc.surrey. ac.uk/7/4/1.html

Rappaport, R. A. (1967). Ritual regulation of environmental relations among a New Guinea people. Ethnology, 6(1), 17-30.

Reid, R., Nkedianye, D., Said, M., Kaelo, D., Neselle, M., Makui, O., Onetu, L., Kiruswa, S., Ole Kamuaro, S., Kristjanson, P., BurnSilver, S., Goldman, M., Boone, R., Galvin, K. A., Dickson, N., \& Clark, W. (2009). Evolving models to support communities and policy makers with science: Balancing pastoralism and wildlife conservation in East Africa. Proceedings of the National Academy of Science. doi:10.1073/pnas.0900313106.

Reynold, C. W. (1987). Flocks, herds, and schools: A distributed behavioral model. Computer Graphics, 21(4), 25-34.

Richiardi, M., Leombruni, R., Saam, N., \& Sonnessa M. (2006). A common protocol for agent-based social simulation. Journal of Artificial Societies and Social Simulation, 9(1), 15. http://jasss.soc.surrey.ac.uk/9/1/15.html

Robbins, P. (2012). Political ecology. Malden: Wiley-Blackwell.

Schelling, T. C. (1971). Dynamic models of segregation. Journal of Mathematical Sociology, $1,143-186$.

Schneider, D. C. (2001). The rise of the concept of scale in ecology. BioScience, 51(7), 545-553.

Talen, E. (2000). Bottom-up GIS: A new tool for individual and group expression in participatory planning. Journal of the American Planning Association, 66(3), 279-294.

Thomas, R. B. (1976). Energy flow at high altitude. In P. T. Baker \& M. Little (Eds.), Man in the Andes (pp. 379-404). Stroudsburg: Dowden, Hutchinson \& Ross.

Thornton, P. K., Galvin, K. A., \& Boone, R. B. (2003). An agro-pastoral household model for the rangelands of East Africa. Agricultural Systems, 76(2), 601-622.

Thornton, P. K., Fawcett, R. H., Galvin, K. A., Boone, R. B., Hudson, J. W., \& Vogel, C. H. (2004). Evaluating management options that use climate forecasts: Modelling livestock production systems in the semi-arid zone of South Africa. Climate Research, 26(1), 33-42.

Thornton, P. K., BurnSilver, S. B., Boone, R. B., \& Galvin, K. A. (2006). Modelling the impacts of group ranch subdivision on agro-pastoral households in Kajiado, Kenya. Agricultural Systems, 87(3), 331-356.

Treiber, M. (2011). Microsimulation of road traffic flow. Dynamic traffic simulation applet. http://www.traffic-simulation.de. Accessed 22 June 2012.

Treiber, M., \& Kesting, A. (2010). An open-source microscopic traffic simulator. IEEE Intelligent Transportation Systems Magazine, 2(3), 6-13.

Turchin, P. (2001). Does population ecology have general laws? Oikos, 94(1), 17-26.

Vayda, A. P., \& McCay, B. (1975). New directions in ecology and ecological anthropology. Annual Review of Anthropology, 4, 293-306.

Watts, M. J. (1997). Classics in human geography revisited: P.M. Blaikie: The political economy of soil erosion in developing countries. Progress in Human Geography, 21, 75-80.

Wilensky, U. (2001). Modeling nature's emergent patterns with multi-agent languages. Proceedings of EuroLogo 2001, Linz, Austria.

Wilensky, U., \& Rand, W. (2007). Making models match: Replicating an agent-based model. Journal of Artificial Societies and Social Simulation, 10(4), 2. URL: http://jasss.soc.surrey. ac.uk/10/4/2.html

Worden, J. S. (2007). Settlement pattern and fragmentation in Maasailand: implications for pastoral mobility, drought vulnerability, and wildlife conservation in an East African savanna. Dissertation submitted to the Graduate Degree Program in Ecology. Colorado State University, Fort Collins. 